\title{
A diversidade na legislação sobre bibliotecas públicas no Brasil e Espanha
}

\author{
Heloá Cristina Oliveira-DelMassa ${ }^{I}$ \\ http://orcid.org/0000-0003-2466-6678 \\ José Antonio Frías ${ }^{I I}$ \\ http://orcid.org/0000-0002-5425-8950 \\ Oswaldo Francisco de Almeida Junior ${ }^{I I I}$ \\ http://orcid.org/0000-0003-3629-7435 \\ ${ }^{I}$ Universidade Estadual Paulista, Marília, SP, Brasil. \\ Doutoranda em Ciência da Informação. \\ II Universidade de Salamanca, Salamanca, Espanha. \\ Professor titular do Departamento de Biblioteconomía y Documentación. \\ III Universidade Estadual de Londrina, Londrina, PR, Brasil. \\ Professor associado da UEL e professor titular do Programa de Pós-graduação \\ em Ciência da Informação da UNESP.
}

http://dx.doi.org/10.1590/1981-5344/3829

As bibliotecas públicas se encontram frente a um público diversamente vivo, mesmo que muitas vezes oprimido. $A$ proposta de uma atuação mediadora prevê uma relação de aproximação constante aos leitores a fim de promover políticas internas e atividades que busquem a apropriação da informação, respeitando e favorecendo a diversidade. Esse trabalho parte do questionamento: as bibliotecas públicas têm sido amparadas por uma legislação que promove e fortalece a diversidade cultural? Para responder, é proposta uma análise inicial da legislação para Bibliotecas Públicas do Brasil e Espanha, buscando a menção da questão da diversidade dentro das leis mais 
gerais de cada país. As leis qualitativamente selecionadas (sendo, para o Brasil, o Plano Nacional do Livro, a Lei no 13.696, de 12 de julho de 2018, que institui a Política Nacional de Leitura e Escrita, e o caderno do Plano Nacional do Livro e Leitura - PNLL e, para a Espanha, o Regulamento de Bibliotecas Públicas del Estado y del Sistema Español de Bibliotecas - Real Decreto 582/1989, e as leis: Ley 10/2007, Ley 19/2006 e Ley 5/2012) foram analisadas com uso da Análise de Discurso. Após as análises foi possível identificar, no caso brasileiro, que os documentos assumem uma posição de livro, leitura e escrita que apresenta uma "poetização" do acesso e acaba por desconsiderar as nuances da apropriação e, no caso da Espanha, observou-se avanços na perspectiva deste estudo (mesmo que de forma isolada), que não só trazem o tema como relevante, mas também apresentam linhas de ação correspondentes. Concluiu-se a expressão da predominância do paradigma custodial e o insuficiente reconhecimento da diversidade cultural como um fator de impacto nas legislações avaliadas.

Palavras-chave: Políticas públicas. Bibliotecas públicas. Diversidade cultural. Mediação.

\section{The diversity in legislation on public libraries in Brazil and Spain}

Public libraries are in face a diverse public, and often oppressed. The proposal of a mediating action foresees a constant rapprochement with readers in order to promote internal policies and activities that seek the appropriation of information, respecting and favoring the diversity. This work starts from the question: have public libraries been supported by a legislation that promote and strengthen the cultural diversity? To answer is proposed an initial analysis of the legislation for Public Libraries of Brazil and Spain, seeking to mention of the diversity within the most general laws of each country. Qualitatively selected laws (for Brazil, the National Book Plan, Law No. 13,696, of July 12, 2018, which establishes the National Reading and 
Writing Policy, and the National Book and Reading Plan PNLL and for Spain, the Regulation of Public Libraries of the State and of the Spanish System of Libraries - Royal Decree 582/1989, and the laws: Law 10/2007, Law 19/2006 and Law 5/2012) were analyzed using Discourses Analysis. After the analyzes, it was possible to identify, in the Brazilian case, that the documents assume a position of book, reading and writing that presents a "poetization" of access and ends up by disregarding the nuances of the appropriation. In the case of Spain, in the perspective of this study (even if in isolation), which not only bring the theme as relevant, but also present corresponding lines of action. It was concluded the predominance of the custodial paradigm and the insufficient recognition of cultural diversity as an impact factor in the legislations evaluated.

Keywords: Public policies. Public libraries. Cultural diversity. Mediation.

Recebido em 14.12.2018 Aceito em 26.08.2019

\section{Introdução}

A diversidade cultural do mundo foi histórica e constantemente massacrada, quase apagada pelas constantes dominações e colonizações que permearam o desenvolvimento humano e a expansão de domínio territorial que, por muitos séculos, dominou o dia a dia da humanidade, principalmente na relação de países considerados desenvolvidos, ou culturas mais amplamente aceitas, sobre novos territórios e novas comunidades.

Desde o século $X X$ as dominações têm assumido diferentes formas, acompanhando o desenvolvimento do mundo e a grande extensão territorial então já percorrida, e focou-se na tentativa de estabelecer aspectos culturais que, consonantes com aspectos políticos dominantes e estrategicamente delineados, mantenham a sociedade numa massa hegemônica passível de dominação e manipulação sempre que necessário.

Porém, mesmo com grandes e constantes tentativas de destruição de culturas consideradas diferentes do culturalmente aceito, moldado em interesses políticos e sociais dominantes, as constantes migrações, a força de determinados movimentos culturais, bem como o próprio reconhecer pessoal de que o culturalmente aceito nem sempre pode representar a 
todos, mantém, até os dias atuais, uma sociedade diversa e rica em costumes e tradições, que luta para não perder sua identidade, ou para criar novas identidades que contemplem sua existência.

As bibliotecas públicas, inseridas numa diversidade de espaços e criadas para atender a sociedade, se encontram, assim, frente a um público diversamente vivo, mesmo que muitas vezes oprimido. A proposta da atuação mediadora em bibliotecas, que é uma das linhas de atuação proposta pela Ciência da Informação e, em especial pela Biblioteconomia, prevê uma relação de aproximação constante aos leitores que as frequentam ou podem frequentá-las, a fim de promover políticas internas e atividades que busquem a apropriação da informação por parte de seus leitores, respeitando e favorecendo sua diversidade. Porém, em vista dessa existência de diferentes grupos culturais em sociedades complexas e muitas vezes opressoras, a atividade de conhecer e respeitar a diversidade cultural pode se tornar um desafio, principalmente se a existência dessa instituição não tiver o amparo legal e liberdade para uma atuação que assim a permita atuar. Ressaltando que "[...] O processo de formulação legislativa, a promulgação da lei e a sua entrada em vigor constituem evidências da relevância que as autoridades responsáveis atribuem à biblioteca pública e ao serviço que ela presta aos cidadãos." (PARREIRA, 2018, p. 293).

Dado esse panorama, questiona-se se as bibliotecas têm sido amparadas por legislações que possuem concordância com uma perspectiva culturalmente dominante, neutra, ou que visa a promoção e fortalecimento da diversidade cultural. Para isso, é proposta uma análise das políticas públicas gerais que amparam a existência e criação de bibliotecas públicas do Brasil e Espanha, com uso da metodologia de Análise de Discurso, para identificar qual a posição adotada em esses documentos com relação ao papel das bibliotecas públicas e a preservação da diversidade cultural.

Após a consulta das leis disponíveis nos canais oficiais de ambos os países analisados (Brasil: Diário Oficial da União; Espanha: Boletín Oficial del Estado), e tendo em consideração as especificidades que serão apresentadas no tópico 3 Metodologia, os documentos utilizados para a aplicação da Análise de Discurso foram: Brasil: Plano Nacional do Livro; a Lei no 13.696, de 12 de julho de 2018, que institui a Política Nacional de Leitura e Escrita; e o caderno do Plano Nacional do Livro e Leitura - PNLL, Espanha: Regulamento de Bibliotecas Públicas del Estado y del Sistema Español de Bibliotecas.

A execução deste trabalho visou demonstrar como os documentos amplos analisados tratam o tema da diversidade, entendendo-o como 
primordial no trabalho bibliotecário dada a complexidade das sociedades em que as bibliotecas estão inseridas e os desafios dos profissionais frente a tal realidade. Vislumbra-se ressaltar a importância do apoio legislativo frente ao tema, que ainda carece de ampliação e esclarecimentos.

Salientamos que, ainda que existam outras iniciativas que possam impactar na tratativa do tema dentro dos países, o objetivo deste trabalho é analisar as leis mais amplas e disponíveis em canais oficias, tendo em vista que seriam estes a base, por assim dizer, do desenvolvimento de outros projetos, leis e iniciativas de diferentes esferas. Deixamos, portanto, a sugestão de que futuros trabalhos abordem outros documentos, de outras esferas e disponíveis em outras bases, a fim de ampliar o estudo do tema.

\section{Pressupostos Teóricos}

Os paradigmas atuais das áreas da Ciência da Informação questionam, entre outros aspectos, as correntes que embasam nossos estudos. O paradigma custodial, que supervaloriza a guarda (a custódia) e os tratamentos dos suportes, com um foco que exalta uma cultura nacionalista e privilegiada, e o pós-custodial, que problematiza e valoriza o contexto social (MALHEIRO; RIBEIRO, 2011), vem dialogando entre as diferentes esferas dos serviços e teorias trabalhados.

Inseridos em um grande processo globalizado, Suaiden (2000, p. 57) ressalta a existência de "novos paradigmas tecnológicos e sociais e do modelo de desenvolvimento sustentável" e esclarece que nesse aspecto "caberá à biblioteca pública trabalhar no sentido de corrigir as deficiências do passado, como criar uma interação adequada com a comunidade e implantar produtos que de fato facilitem 0 acesso à Sociedade da Informação.".

Independente dos paradigmas adotados, e sua convergência ou não, a biblioteca pública deve dotar-se de valores essenciais, valores esses pouco descritos e discutidos na maioria das legislações sobre o tema mas que, conforme destacado por Hapel (2000), deveriam ter mundialmente um eixo comum, que transpassariam o próprio uso das tecnologias, superando sua "frieza":

[...] assegurar o acesso livre e igualitário à informação e ao conhecimento; assegurar a formação livre de opinião; fortalecer a habilidade de leitura; levar adiante a disseminação cultural; fortalecer as habilidades criativas e analíticas pessoais; apoiar a diversidade cultural; e fortalecer o conhecimento das novas possibilidades tecnológicas. (HAPEL, 2000 apudd PAIVA, 2008, p. 21-22). 
Neste trabalho reconhece-se que os valores acima descritos seriam a base para a busca de um apoio legal para o desenvolvimento de serviços que, dentro (ainda que não fisicamente) da biblioteca pública, apoiassem um dos aspectos mais fragilizados de sua atuação - o apoio à diversidade cultural - fragilidade ressaltada não apenas por sua complexidade, mas também por representar um luta contra a supervalorização de uma cultura dominante em detrimento de outras em um país ou sociedade. Essa atuação se fundamenta em relações sociais que envolvem diferenças, numa pluralidade cultural infindável que tece nosso "tecido social" (RASTELI; CALDAS, 2017, p. 44).

Suaiden (2000, p. 60) expõe que ao vincular-se adequadamente à comunidade a biblioteca pública assumiria o papel de "caminho" para que a comunidade desenvolva uma "participação efetiva na sociedade da informação", e que

[...] Isso é de extraordinária importância em um país onde a desinformação atinge altas proporções, e, sem essa oportunidade, milhares de pessoas jamais terão oportunidade de entender e de ter noção dos seus direitos e deveres em uma sociedade globalizada, pois o acesso à informação, nos novos tempos, significa o investimento adequado para diminuir as desigualdades sociais e as formas de dominação que foram dominantes na história contemporânea. (SUAIDEN, 2000, p. 60).

Mesmo 19 anos após a publicação do texto supracitado, ainda há a missão de aproximação exposta, em uma função social em construção, já abordada também em manifestos da Federação Internacional de Associações e Instituições Bibliotecárias - IFLA, Centro Regional para o Fomento do Livro na América Latina e o Caribe - CERLALC e Organização das Nações Unidas para a Educação, a Ciência e a Cultura - UNESCO (IFLA; UNESCO, 2008; CERLALC et al., 1982).

Entre essa necessidade de valorização do social, as políticas públicas para bibliotecas podem ter um destaque estratégico, servindo para "mudanças sociais que têm como princípio a igualdade social, sendo, portanto, um processo dinâmico, permanente e contínuo, contraditório, fruto geralmente da ação e/ou posição dos vários movimentos sociais nos estados capitalistas." (FERREIRA, 2006, p. 115).

A necessidade de embasamento legal, e os embates entre os diferentes pesos, por assim dizer, que se pode agregar ao conceito e abrangência do papel da biblioteca pública, quebra uma teoria já muito reproduzida nesse âmbito - o da neutralidade da informação, conforme exposto por Almeida Júnior: 
A informação também é considerada neutra, pois existe concretamente e se adapta perfeitamente a um usuário, sem que se o conheça ou se saiba algo sobre a necessidade que o levou à biblioteca. Esse é o pensamento presente na maioria dos bibliotecários que atuam em bibliotecas públicas. Informação é considerada como algo real, material, tangível, que existe solta no mundo, bastando adequá-la ao pedido do usuário. A informação é entendida apenas sob o aspecto técnico, ou seja, uma "mercadoria" passível de ser moldada por si só, sem uma análise das implicações sociais e políticas decorrentes de sua manipulação e disseminação. A informação, na medida em que está armazenada na biblioteca, perde todas as influências, as interferências, as ideologias, as concepções inerentes a ela. Pode ser oferecida para qualquer pessoa, independente de seus interesses, seus conhecimentos prévios, os objetivos para os quais será utilizada e empregada etc. Pode-se excluir, pensando dessa forma, o usuário do processo de referência. (ALMEIDA JúNIOR, 2013, p. 82-83).

Esse pensamento neutro que reina em muitos espaços e profissionais se reproduz na vertente legal, como contatado por Paiva (2008) que, num estudo aprofundado da legislação de bibliotecas públicas brasileiras de 1990 a 2006, constatou a reprodução dos ideais simplistas de institutos e programas que, sem uma continuidade de seus antecessores, trazem apenas questões da criação de bibliotecas num âmbito que, segundo a autora,

[...] representa o fracasso das políticas para bibliotecas públicas, que não conseguiram ainda prover o básico: fazer existirem as bibliotecas públicas em todo território. Uma outra conclusão que se pode tirar dessas reedições de um mesmo objetivo em documentos diferentes é a descontinuidade administrativa. Mesmo quando já existia um programa com o objetivo de universalizar as bibliotecas públicas no País, o governo sucessor preferiu não dar continuidade e aprimorar esse programa, mas fazer um "novo", dar-lhe um novo nome, nomear outro diretor, sobrepondo objetivos e dispersando energia e recursos, além de desperdiçar todo o conhecimento acumulado, as relações estabelecidas, as experiências que evitam a repetição dos erros. (PAIVA, 2008, p. 111).

$\mathrm{Na}$ atual crise mundial de direitos humanos, explicitada por eventos que têm trazido a discussão princípios já anteriormente considerados superados, como o direito à informação, liberdade de expressão e a própria valorização dos direitos humanos, tais constatações se mostram ainda mais urgentes.

O que se observou e ainda se observa é que as políticas de bibliotecas muitas vezes se apegam ao material, com foco em compra de livros, equipamentos, mobiliários etc. (PAIVA, 2008), sem ater-se às 
questões complexas que permeiam, ou ao menos deveriam permear, a existência democrática de uma biblioteca pública.

A IFLA e a UNESCO (2008), em seu manifesto por uma Biblioteca Multicultural, esclarecem ainda que, não apenas as bibliotecas públicas mas sim qualquer biblioteca, precisa servir a comunidades diversamente constituídas, assumindo uma posição de "centros de aprendizagem, cultura e informação", proporcionando serviços que em respeito a essa diversidade cultural e linguística assumam o compromisso das bibliotecas com os princípios de liberdade e igualdade no acesso à informação e conhecimento, respeitando a identidade e os valores culturais da sociedade.

Dentro desse contexto e visando ater-se ao objetivo deste trabalho, que é identificar aspectos da diversidade em legislações brasileiras e espanholas acerca das bibliotecas públicas, o tópico 3 explicitará o caminho metodológico seguido para execução da pesquisa proposta.

\section{Metodologia}

Os aspectos que nortearam a escolha dos documentos para essa pesquisa foram:

\section{Brasil}

O Plano Nacional do Livro e Leitura - PNLL, instituído pelos ministros da Cultura e da Educação (Portaria Interministerial No 1.442, de 10 de agosto de 2006) e, em 10 de setembro de 2011, instituído por meio do decreto No 7.559, firmado pela então presidenta Dilma Rousseff, apresenta as diretrizes para uma política pública voltada à leitura e ao livro no Brasil e é orientado por 4 eixos: EIXO 1 - Democratização do acesso; EIXO 2 - Fomento à leitura e à formação de mediadores; EIXO 3 Valorização institucional da leitura e incremento de seu valor simbólico; e EIXO 4 - Desenvolvimento da economia do livro (BRASIL. Ministério da Cultura, 2018).

O PNLL enfatiza que seus eixos não se tratam da:

[...] explicitação de um conjunto de iniciativas e ações a serem efetivamente desenvolvidas pelo Governo Federal. Trata-se da fixação, do delineamento e da sistematização dessas iniciativas e ações, de tal modo que o conjunto dos eixos possa servir como baliza clara para que as mais variadas instituições e entidades da sociedade planejem e implementem suas ações, concentrando o foco nas prioridades do setor e não dispersando recursos de qualquer natureza." (BRASIL. Ministério da Cultura, 2014, p. 27). 
O I Eixo do PNLL (Democratização do Acesso) possui o tópico "1.1 Implantação de novas bibliotecas", onde expõe a seguinte descrição:

Implantação de novas bibliotecas de acesso público, estaduais, municipais e escolares (com acervos que atendam, pelo menos, aos mínimos recomendados pela UNESCO, incluindo livros em braille, livros digitais, audiolivros etc, computadores conectados à internet, jornais, revistas e outras publicações periódicas) e funcionando como centros de ampla produção e irradiação cultural. Criação de bibliotecas comunitárias (periferias urbanas, morros, hospitais, creches, igrejas, zonas rurais, clubes de serviços, ONGs etc). (BRASIL. Ministério da Cultura, 2014, p. 27-28).

Em 2018 o Ministério da Cultura (MinC) lançou um edital para Bibliotecas Digitais. O departamento do ministério responsável pelas bibliotecas do país não lançava um edital desde 2015 e, conforme salientado pela assessoria do MinC:

Em sintonia com as novas tecnologias, o edital Bibliotecas Digitais destinará $R$ \$ 2 milhões ( $R$ \$ 100 mil por convênio) para fomentar a criação do conceito de biblioteca digital em vinte bibliotecas públicas estaduais ou municipais do país. O edital prevê a aquisição de leitores de livros digitais (e-readers) e de licenças e direitos para acesso digital a conteúdos e livros, além de ações de modernização e adequação da estrutura, tornando os espaços mais atrativos. (Brasil, Assessoria de Comunicação, Ministério da Cultura, 2018).

\section{Espanha}

A criação de uma biblioteca pública depende de ordem do Ministro de Cultura ou de Real Decreto, e as bibliotecas públicas estão sob o regimento da lei 16/1985, de 25 de junho, do Patrimônio Real Espanhol (Real Decreto 582/1989, de 19 de mayo). O Real Decreto 582/1989 apresenta o Regulamento das Bibliotecas Públicas do Estado, definindo a natureza e funções específicas desses órgãos, bem como estabelece "as normas fundamentais para o tratamento administrativo e técnico dos fundos; as condições de acesso para o público" e define "os serviços mínimos que se deve oferecer aos usuários" (Real Decreto 582/1989, de 19 de mayo).

Parreira apresenta as seguintes informações:

Em Espanha, as bibliotecas públicas são regulamentadas a nível nacional e de forma geral pela Ley 10/2007 de 22 de junio, de la lectura, del libro y de las bibliotecas, e com carácter mais específico por leis regionais de bibliotecas, promulgadas pelas respetivas Comunidades Autónomas a partir de 1983. Das 17 comunidades e duas cidades autónomas que compõem o território espanhol, apenas em duas comunidades (Astúrias e Canárias) e nas duas cidades 
autónomas de Ceuta e Melilla não existe lei regional de bibliotecas. (PARREIRA, 2018, p. 152)

A atividade cultural a nível local é regulamentada pela Lei 71/85 do Regime Local, de 2 de abril, que delega nos municípios a gestão do património, das atividades culturais e de lazer, com base na maior proximidade dos cidadãos (Espanha, 1985). No que concerne às bibliotecas, a Lei determina que todas as localidades com mais de 5.000 habitantes devem obrigatoriamente disponibilizar serviços de biblioteca pública. (PARREIRA, 2018, p. 156)

[...] país conta com quase 1500 normas, incluindo leis, decretos, documentos normativos e documentos institucionais, de âmbito nacional e regional, relativos à atividade das bibliotecas. As normas incidem sobre temas como a organização do sistema de bibliotecas, a Biblioteca Nacional de Espanha, o depósito legal e o ISBN, o empréstimo, a propriedade intelectual, a proteção do património e 0 acesso à informação. (PARREIRA, 2018, p. 158)

E as leis das comunidades autônomas, segundo Villaroya e AtecaAmestoy, são:

Quadro 1 Leis de bibliotecas promulgadas nas Comunidades Espanholas

\begin{tabular}{|l|l|}
\hline \multicolumn{1}{|c|}{ Comunidade } & \multicolumn{1}{c|}{ Identificação da Lei } \\
\hline Catalunha & Lei $3 / 1981$, substituída pela Lei $4 / 1993$ \\
\hline Andaluzia & Lei $8 / 1983$, substituída pela Lei $16 / 2003$ \\
\hline Valência & Lei $10 / 1986$, substituída pela Lei $4 / 2011$ \\
\hline Aragão & Lei $8 / 1986$ \\
\hline Castela e Leão & Lei $9 / 1989$ \\
\hline Castela-La Mancha & Lei $1 / 1989$, substituída pela Lei 3/2011 \\
\hline Galiza & Lei $14 / 1989$, substituída pela Lei $5 / 2012$ \\
\hline Madrid & Lei $10 / 1989$ \\
\hline Rioja & Lei $4 / 1990$ \\
\hline Murcia & Lei $7 / 1990$ \\
\hline Extremadura & Lei $6 / 1997$ \\
\hline Cantabria & Lei 3/2001 \\
\hline Navarra & Lei 32/2002 \\
\hline Baleares & Lei $19 / 2006$ \\
\hline País Basco & Lei $11 / 2007$ \\
\hline
\end{tabular}

Fonte: VILLAROYA; ATECA-AMESTOY, 2015 apud PARREIRA, 2018, p. 159.

Dentre as supracitadas leis, após conferência na página web do Boletín Oficial del Estado ${ }^{1}$, podemos atualizar a que corresponde à Comunidade de Aragão: Lei 7/2015.

${ }^{1}$ Disponível no endereço eletrônico: https://www.boe.es/. 
Em busca no Boletín Oficial del Estado, por leis vigentes, com os termos "biblioteca pública" e "diversidade cultural", obtivemos 3 resultados:

Ley 10/2007, de 22 de junio, de la lectura, del libro y de las bibliotecas. Jefatura del Estado (BOE 150 de 23/06/2007)

Ley 19/2006, de 23 de noviembre, del Sistema Bibliotecario de las Illes Balears. Comunidad Autónoma de las Illes Balears (BOE 303 de 20/12/2006)

Ley 5/2012, de 15 de junio, de bibliotecas de Galicia. Comunidad Autónoma de Galicia (BOE 161 de 06/07/2012)

Assim, para selecionar a amostra analisamos:

Para o Brasil: Documentação disponível em bases de dados que discutissem as atuais políticas vigentes no país, priorizando datas mais recentes de publicação; e os resultados obtidos através do portal Diário Oficial da União.

Para Espanha: Documentação disponível em bases de dados que discutissem as atuais políticas vigentes no país, priorizando datas mais recentes de publicação; os documentos legais espanhóis das 15 províncias que possuem legislação específica para bibliotecas; e os resultados obtidos através do portal Boletim Oficial do Estado, com os descritores "diversidade cultural" e "bibliotecas", nos quais excluímos os que já estavam na amostra inicial (leis das províncias).

Após essas análises iniciais, os documentos qualitativamente escolhidos para a aplicação da AD foram:

Brasil: O Plano Nacional do Livro; a Lei no 13.696, de 12 de julho de 2018, que institui a Política Nacional de Leitura e Escrita; e o caderno do Plano Nacional do Livro e Leitura PNLL.

Espanha: O Regulamento de Bibliotecas Públicas del Estado y del Sistema Español de Bibliotecas (Real Decreto 582/1989) e as leis: Ley 10/2007, Ley 19/2006 e Ley 5/2012.

\subsection{Análise de Discurso}

Foi empregada a Análise de Discurso (AD) para analisar os documentos selecionados. A escolha dessa metodologia foi baseada na importância que ela agrega ao contexto social da análise, trabalhando com o indivíduo e a linguagem em sua historicidade. (Silva, 2005). 
Orlandi (2007, p. 59) esclarece que na AD "[...] a proposta é a da construção de um dispositivo de interpretação. Esse dispositivo tem como característica colocar o dito em relação ao não dito, [...] procurando ouvir, naquilo que o sujeito diz, aquilo que ele não diz mas que constitui igualmente os sentidos de suas palavras".

Buscou-se a análise da materialidade linguística, isto é, a partir do que é expresso, do que é dito, procurar pistas que possibilitem a compreensão do modo de textualização desse discurso, demonstrando suas relações de sentido e força (de que lugar se fala?), visando dar conta da identificação do que é dito não só em um discurso, mas também em outras diferentes condições, abarcando diversas memórias discursivas. Assume-se, portanto, que existe uma relação "entre diferentes superfícies linguísticas face ao processo discursivo. Com isto detectamos a relação do discurso com as formações discursivas". (ORLANDI, 2007, p. 65-66) O objetivo é, porquanto, a identificação do contexto discursivo que ocasionou a textualização.

Para a análise proposta, estabeleceu-se as seguintes categorias extraídas das bases da AD:

1a CATEgORIA: Superfície Linguística (o que é dito)

$2^{\text {a }}$ CATEGORIA: Argumentos e fundamentos (onde é dito)

3a CATEGORIA: Manifestações (porque é dito)

Reprodução Ideológica / Reconhecimento / Linhas de ação

Quando algo é dito, transparece seu contexto, suas influências, e, finalmente, clarifica-se a posição manifestada. O estabelecimento dessas três categorias visa separar e destacar tais contextos, influências e posições nos discursos analisados.

A primeira categoria visa organizar o conteúdo encontrado sobre o que se objetiva analisar da forma exata em que foram expressas, demonstrando a superfície do discurso. A segunda categoria preocupa-se com a identificação dos argumentos e fundamentos, o transparecer de suas influências passadas e atuais, suas influências ideológicas e sociais. Finalmente, a terceira categoria se mostra composta por três subsequentes categorias. O objetivo principal nesta etapa é identificar a posição adotada pelo texto, o cerne de sua manifestação. Tal posicionamento pode ser considerado uma Reprodução Ideológica (pela repetição de uma ideologia imposta histórica, política e/ou socialmente); um Reconhecimento, que seria expresso por manifestações que superem 
a reprodução; ou uma posição de Linhas de Ação, na qual se evidenciaria propostas de ação ou orientação que demonstrem relação direta com o tema abordado.

\section{Resultados e discussões}

\subsection{Brasil} Quadro 2 - Caderno do Plano Nacional do Livro e Leitura - PNLL (BRASIL.
Ministério da Cultura, 2018): aplicação da AD.

\begin{tabular}{|c|c|c|c|}
\hline $\begin{array}{c}\text { TÓPICO/ } \\
\text { CONTEXTO }\end{array}$ & SUPERFÍCIE LINGUÍSTICA & $\begin{array}{l}\text { ARGUMENTOS E } \\
\text { FUNDAMENTOS }\end{array}$ & MANIFESTAÇÕES \\
\hline Justificativa & $\begin{array}{l}\text { Para fortalecer qualquer política ou } \\
\text { ação ligada ao livro, é preciso uma } \\
\text { valorização da esfera da cultura } \\
\text { como um todo, franqueando o } \\
\text { acesso a uma variada gama de } \\
\text { objetos culturais que hoje } \\
\text { estabelecem vínculos estreitos com } \\
\text { os livros. Há de se considerar a } \\
\text { diversidade cultural de inúmeras } \\
\text { instâncias - e não apenas a escola - } \\
\text { que influencia a cultura, tais como a } \\
\text { família, a mídia, as instituições } \\
\text { voltadas ao lazer, à religião, à } \\
\text { política etc. }\end{array}$ & $\begin{array}{l}\text { Para fortalecer qualquer } \\
\text { política ou ação ligada ao } \\
\text { livro, é preciso uma } \\
\text { valorização da esfera da } \\
\text { cultura como um todo. } \\
\text { Objetos culturais } \\
\text { estabelecem vínculos } \\
\text { estreitos com os livros. } \\
\text { Considerar a diversidade } \\
\text { cultural de inúmeras } \\
\text { instâncias consideradas } \\
\text { como influentes da } \\
\text { cultura. }\end{array}$ & $\begin{array}{l}\text { Reprodução ideológica: } \\
\text { centralização do livro. } \\
\text { Reconhecimento: } \\
\text { diversidade cultural em } \\
\text { inúmeras instâncias. }\end{array}$ \\
\hline $\begin{array}{l}\text { Princípios } \\
\text { Norteadores. } \\
\text { Diversidade } \\
\text { Cultural. }\end{array}$ & $\begin{array}{l}\text { A leitura e a escrita são, na } \\
\text { contemporaneidade, instrumentos } \\
\text { decisivos para que as pessoas } \\
\text { possam desenvolver de maneira } \\
\text { plena seu potencial humano e } \\
\text { caracterizam-se como fundamentais } \\
\text { para fortalecer a capacidade de } \\
\text { expressão da diversidade cultural } \\
\text { dos povos, favorecendo todo tipo de } \\
\text { intercâmbio cultural; são requisitos } \\
\text { indispensáveis para alcançar níveis } \\
\text { educativos mais altos; apresentam- } \\
\text { se como condição necessária para o } \\
\text { desenvolvimento social e } \\
\text { econômico. A leitura e o livro são } \\
\text { vistos neste Plano não apenas em } \\
\text { uma dimensão educacional, mas } \\
\text { também em uma perspectiva } \\
\text { cultural, na qual se reconhecem três } \\
\text { dimensões trabalhadas pela atual } \\
\text { gestão do Ministério da Cultura }\end{array}$ & $\begin{array}{l}\text { Leitura e a escrita como } \\
\text { instrumentos para que as } \\
\text { pessoas possam } \\
\text { desenvolver plenamente } \\
\text { seu "potencial humano", } \\
\text { fundamentais para } \\
\text { fortalecer a capacidade de } \\
\text { expressão da diversidade } \\
\text { cultural e favorecer todo } \\
\text { tipo de intercâmbio } \\
\text { cultural; como requisitos } \\
\text { indispensáveis para } \\
\text { alcançar níveis educativos } \\
\text { mais altos; e como } \\
\text { condição necessária para } \\
\text { o desenvolvimento social } \\
\text { e econômico. }\end{array}$ & $\begin{array}{l}\text { Reprodução ideológica: } \\
\text { centralização e } \\
\text { supervalorização da } \\
\text { leitura e escrita. }\end{array}$ \\
\hline $\begin{array}{l}\text { Objetivos e } \\
\text { Metas. São } \\
\text { estabelecidos } \\
\text { aqui, com a } \\
\text { aprovação do } \\
\text { Colegiado } \\
\text { Setorial do } \\
\text { Livro, Leitura e } \\
\text { Literatura do } \\
\text { MinC, alguns } \\
\text { objetivos que } \\
\text { devem ser } \\
\text { alcançados no } \\
\text { curto, médio e }\end{array}$ & $\begin{array}{l}\text { r) Incentivar e fomentar a } \\
\text { constituição de acervos que } \\
\text { garantam a produção local, territorial } \\
\text { e nacional, que preservem a } \\
\text { memória e contribuam para o } \\
\text { entendimento da diversidade cultural } \\
\text { brasileira; }\end{array}$ & $\begin{array}{l}\text { Incentivar e fomentar } \\
\text { acervos que garantam a } \\
\text { produção local, territorial e } \\
\text { nacional, que preservem a } \\
\text { "memória" e contribuam } \\
\text { para o "entendimento da } \\
\text { diversidade brasileira" }\end{array}$ & $\begin{array}{l}\text { Reconhecimento: } \\
\text { necessidade de acervo } \\
\text { <diverso>, preservação } \\
\text { da memória e } \\
\text { entendimento da } \\
\text { diversidade brasileira. }\end{array}$ \\
\hline
\end{tabular}


longo prazos.

Quadro 3 - Lei no 13.696, de 12 de julho de 2018 (BRASIL, 2018): aplicação da AD.

\begin{tabular}{|c|c|c|c|}
\hline $\begin{array}{l}\text { TÓPICO/ } \\
\text { CONTEXTO }\end{array}$ & SUPERFÍCIE LINGUÍSTICA & E & MAN \\
\hline $\begin{array}{l}\text { O } \\
\text { PRESIDENTE } \\
\text { DA } \\
\text { REPÚBLICA. } \\
\text { Faço saber que } \\
\text { o Congresso } \\
\text { Nacional } \\
\text { decreta e eu } \\
\text { sanciono a } \\
\text { seguinte Lei: }\end{array}$ & $\begin{array}{l}\text { Art. 10 Fica instituída a Política } \\
\text { Nacional de Leitura e Escrita como } \\
\text { estratégia permanente para } \\
\text { promover o livro, a leitura, a } \\
\text { escrita, a literatura e as bibliotecas } \\
\text { de acesso público no Brasil. } \\
\text { Art. 4ํ Para a consecução dos } \\
\text { objetivos da Política Nacional de } \\
\text { Leitura e Escrita, será elaborado, a } \\
\text { cada decênio, o Plano Nacional do } \\
\text { Livro e Leitura (PNLL), que } \\
\text { estabelecerá metas e ações, nos } \\
\text { termos de regulamento. }\end{array}$ & $\begin{array}{l}\text { Política Nacional como } \\
\text { estratégia permanente } \\
\text { para promover o livro, } \\
\text { a leitura, a escrita, a } \\
\text { literatura e as } \\
\text { bibliotecas de acesso } \\
\text { público no Brasil. } \\
\\
\text { PNLL como } \\
\text { responsável por metas } \\
\text { e ações atualizadas } \\
\text { regulamentárias. }\end{array}$ & $\begin{array}{l}\text { Reprodução } \\
\text { ideológica: Política } \\
\text { Nacional como } \\
\text { estratégia } \\
\text { permanente para } \\
\text { promoção do livro, } \\
\text { leitura, escrita, } \\
\text { literatura e as } \\
\text { bibliotecas de } \\
\text { acesso público no } \\
\text { Brasil. }\end{array}$ \\
\hline
\end{tabular}

Observação: Não há nenhuma menção à diversidade cultural.

No PNLL identificamos a reprodução ideológica da centralização do livro e da centralização e supervalorização da leitura e escrita, e um reconhecimento da diversidade cultural em inúmeras instâncias e da necessidade de um acervo <diverso>, bem como a preocupação com a preservação da memória e entendimento da diversidade brasileira.

Na lei no 13.696, de 12 de julho de 2018 não há nenhuma menção à diversidade cultural. Identificamos apenas a reprodução ideológica de que uma Política Nacional atua como estratégia permanente para promoção do livro, leitura, escrita, literatura e as bibliotecas de acesso público e a reafirmação da importância do PNLL.

\subsection{Espanha}

Quadro 4 - Galicia - Ley 5/2012, de 15 de junio, de bibliotecas de Galicia (ESPAÑA.

Comunidad Autónoma de Galicia, 2012): aplicação da AD.

\begin{tabular}{|c|c|c|c|}
\hline $\begin{array}{l}\text { TOPICO/ } \\
\text { CONTEXTO }\end{array}$ & SUPERFÍCIE LINGUÍSTICA & $\begin{array}{l}\text { ARGUMENTOS E } \\
\text { FUNDAMENTOS }\end{array}$ & MANIFESTAÇŌES \\
\hline $\begin{array}{l}\text { CAPÍTULO II. } \\
\text { Régimen de } \\
\text { prestación de los } \\
\text { servicios } \\
\text { bibliotecarios. } \\
\text { Artículo } 20 \text {. } \\
\text { Funciones de las } \\
\text { bibliotecas públicas. }\end{array}$ & $\begin{array}{l}\text { Las funciones de las bibliotecas } \\
\text { públicas son: } \\
\text { c) Atender las específicas } \\
\text { necesidades culturales de las } \\
\text { personas y grupos en los que se } \\
\text { integren, promocionando la } \\
\text { diversidad cultural y la atención a } \\
\text { las variables de edad, sexo y } \\
\text { discapacidad. } \\
\text { d) Prestar un apoyo activo } \\
\text { específico a la cultura y la lengua } \\
\text { propias de Galicia. } \\
\text { e) Desarrollar actividades de }\end{array}$ & $\begin{array}{l}\text { Funções das bibliotecas } \\
\text { públicas: } \\
\text { atendimento de } \\
\text { necessidades culturais } \\
\text { específicas de pessoas e } \\
\text { grupos (identificado como } \\
\text { promoção da diversidade } \\
\text { cultural e com atenção às } \\
\text { variáveis de idade, sexo e } \\
\text { deficiência); apoio ativo } \\
\text { específico para cultura e } \\
\text { língua "próprios" de Galícia; } \\
\text { desenvolvimento de }\end{array}$ & $\begin{array}{l}\text { Reconhecimento: } \\
\text { cultura como } \\
\text { necessidade e não } \\
\text { homogênea. } \\
\text { Linhas de ação: } \\
\text { apoio específico a } \\
\text { cultura e língua } \\
\text { considerados } \\
\text { próprios da região; } \\
\text { criação de coleção } \\
\text { ao “interesse } \\
\text { local”; apoio a }\end{array}$ \\
\hline
\end{tabular}




\begin{tabular}{|c|c|c|c|}
\hline & $\begin{array}{l}\text { creación o difusión cultural y de } \\
\text { promoción de la lectura. } \\
\text { f) Recoger, mantener y difundir una } \\
\text { colección de interés local y apoyar } \\
\text { la creación cultural en su territorio. } \\
\text { g) Contribuir a la creación de un } \\
\text { espacio público de debate y } \\
\text { educación social que posibilite la } \\
\text { normal expresión de las libertades } \\
\text { públicas y los derechos } \\
\text { fundamentales de las personas. }\end{array}$ & $\begin{array}{l}\text { atividades de "criação ou } \\
\text { difusão cultural e de } \\
\text { promoção de leitura"; } \\
\text { coleção de interesse local e } \\
\text { apoio a criação cultural; } \\
\text { contribuir para a criação de } \\
\text { espaço público de debate e } \\
\text { educação social. }\end{array}$ & $\begin{array}{l}\text { "criação cultural"; } \\
\text { criação de um } \\
\text { espaço público de } \\
\text { debate e educação } \\
\text { social. }\end{array}$ \\
\hline $\begin{array}{l}\text { CAPITULO II. } \\
\text { Régimen de } \\
\text { prestación de los } \\
\text { servicios } \\
\text { bibliotecarios. } \\
\text { Artículo } 22 \text {. Régimen } \\
\text { de los fondos } \\
\text { bibliográficos. }\end{array}$ & $\begin{array}{l}\text { 2. La adquisición de obras y demás } \\
\text { material cultural para la consulta y } \\
\text { el préstamo obedecerá a criterios } \\
\text { profesionales, de fomento de la } \\
\text { diversidad cultural y de satisfacción } \\
\text { de las demandas de las personas } \\
\text { usuarias. }\end{array}$ & $\begin{array}{l}\text { Aquisição baseada em } \\
\text { critérios profissionais, com } \\
\text { fomento a diversidade } \\
\text { cultural e visando a } \\
\text { satisfação da demanda dos } \\
\text { usuários. }\end{array}$ & $\begin{array}{l}\text { Linhas de ação: } \\
\text { seleção consciente } \\
\text { em relação a } \\
\text { diversidade } \\
\text { cultural. }\end{array}$ \\
\hline
\end{tabular}

\section{Quadro 5 - Illes Balears - Ley 19/2006, de 23 de noviembre, del Sistema Bibliotecario de las Illes Balears (ESPAÑA. Comunidad Autónoma de las Illes Baleares, 2006). : aplicação da AD.}

\begin{tabular}{|c|c|c|c|}
\hline $\begin{array}{l}\text { TOPICO/ } \\
\text { CONTEXTO }\end{array}$ & SUPERFÍCIE LINGUÍSTICA & $\begin{array}{l}\text { ARGUMENTOS E } \\
\text { FUNDAMENTOS }\end{array}$ & MANIFESTAÇŌES \\
\hline $\begin{array}{l}\text { CAPÍTULO I. } \\
\text { Definición y } \\
\text { composición } \\
\text { del Sistema } \\
\text { Bibliotecario de } \\
\text { las Illes } \\
\text { Balears. } \\
\text { Artículo 9. Las } \\
\text { bibliotecas } \\
\text { públicas. }\end{array}$ & $\begin{array}{l}\text { 1. Las bibliotecas públicas son los centros } \\
\text { que proporcionan el acceso al } \\
\text { conocimiento, a la información y a las } \\
\text { obras de creación, a través de una serie } \\
\text { de recursos y servicios de tipo cultural, } \\
\text { educativo, recreativo y social, y están a } \\
\text { disposición de todas las personas de una } \\
\text { comunidad. Son un componente esencial } \\
\text { de cualquier estrategia a largo plazo para } \\
\text { la cultura, la provisión de información, la } \\
\text { alfabetización y la educación. } \\
\text { 3. Las bibliotecas públicas cumplirán las } \\
\text { funciones siguientes: } \\
\text { b) Participar en el fomento y la } \\
\text { normalización lingüística de la lengua } \\
\text { catalana, propia de las Illes Balears. } \\
\text { c) Animar el diálogo intercultural y } \\
\text { favorecer la diversidad cultural. } \\
\text { h) Ser centros culturales activos y } \\
\text { promotores de actividades culturales. } \\
\text { i) Dotar de colecciones y recursos para } \\
\text { atender la diversidad lingüística y cultural } \\
\text { y las demandas de los usuarios con } \\
\text { especial atención a aquellas personas con } \\
\text { necesidades especiales. } \\
\text { j) Recabar, conservar y difundir los } \\
\text { testimonios de la cultura local en cualquier } \\
\text { soporte físico. } \\
\text { k) Promover el conocimiento y el estudio } \\
\text { de las lenguas, especialmente las de } \\
\text { aquellos grupos con representación en la } \\
\text { comunidad, como forma de profundizar la } \\
\text { comunicación. } \\
\text { I) Garantizar el acceso de los ciudadanos } \\
\text { a todo tipo de información de la } \\
\text { comunidad. } \\
\text { 4. Las bibliotecas públicas organizarán }\end{array}$ & $\begin{array}{l}\text { Bibliotecas públicas como } \\
\text { componentes essenciais } \\
\text { para estratégias para a } \\
\text { cultura. } \\
\text { Dentre as funções da } \\
\text { biblioteca pública estão: } \\
\text { fomento e normalização } \\
\text { da língua; animar o } \\
\text { diálogo intercultural e } \\
\text { favorecer a diversidade } \\
\text { cultural; ser um centro } \\
\text { cultural ativo e promotor } \\
\text { de atividades culturais; } \\
\text { dotar de coleções e } \\
\text { recursos para as } \\
\text { demandas de diversidade } \\
\text { linguística e cultural, com } \\
\text { atenção especial a } \\
\text { pessoas com } \\
\text { "necessidades especiais"; } \\
\text { recolher, conservar e } \\
\text { difundir testemunhos da } \\
\text { cultura local em qualquer } \\
\text { suporte físico; promover } \\
\text { conhecimento e estudo de } \\
\text { línguas, especialmente as } \\
\text { de grupos com } \\
\text { representação na } \\
\text { comunidade, como forma } \\
\text { de aprofundar a } \\
\text { comunicação; garantir o } \\
\text { acesso dos cidadãos a } \\
\text { todo tipo de informação } \\
\text { da comunidade. }\end{array}$ & $\begin{array}{l}\text { Linhas de ação: } \\
\text { biblioteca como } \\
\text { centro de ação } \\
\text { cultural; promoção e } \\
\text { ensino de línguas } \\
\text { visando uma } \\
\text { "aproximação" entre } \\
\text { pessoas que falam } \\
\text { diferentes idiomas. }\end{array}$ \\
\hline
\end{tabular}




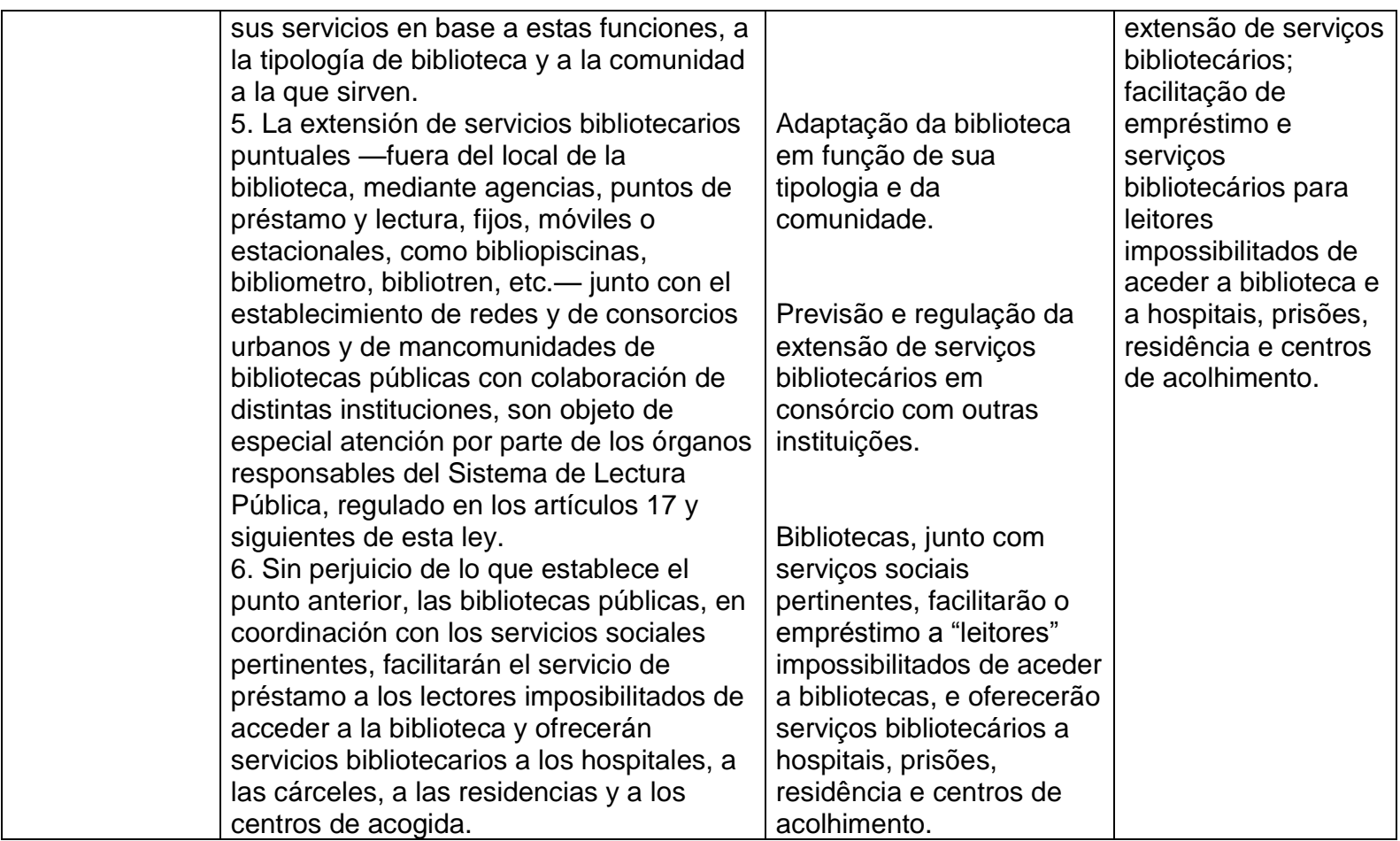

Quadro 6 - Real Decreto-ley: Ley 10/2007, de 22 de junio, de la lectura, del libro y de las bibliotecas (ESPAÑA, 2007): aplicação da AD.

\begin{tabular}{|c|c|c|c|}
\hline $\begin{array}{c}\text { TOPICO/ } \\
\text { CONTEXTO }\end{array}$ & SUPERFICIE LINGUISTICA & $\begin{array}{l}\text { ARGUMENTOS E } \\
\text { FUNDAMENTOS }\end{array}$ & MANIFESTAÇOES \\
\hline $\begin{array}{l}\text { Capítulo III. } \\
\text { Promoción de los } \\
\text { autores y de la } \\
\text { industria del libro. } \\
\text { Artículo } 7 . \\
\text { Promoción de la } \\
\text { industria editorial } \\
\text { y del comercio } \\
\text { del libro. }\end{array}$ & $\begin{array}{l}\text { 1. La Administración General del } \\
\text { Estado y sus organismos públicos } \\
\text { establecerán programas de apoyo a la } \\
\text { industria y al comercio del libro para } \\
\text { garantizar la pluralidad y diversidad } \\
\text { cultural y facilitar el acceso a la lectura } \\
\text { en consideración a los valores } \\
\text { culturales que el libro representa y a su } \\
\text { importancia industrial y económica. } \\
\text { Estos programas tendrán en cuenta a } \\
\text { las librerías no sólo como lugares de } \\
\text { venta de libros, sino también en su } \\
\text { calidad de agentes culturales. }\end{array}$ & $\begin{array}{l}\text { Livrarias como agentes } \\
\text { culturais. } \\
\text { Apoio a indústria e } \\
\text { comércio do livro para } \\
\text { garantir a pluralidade e } \\
\text { diversidade cultural. } \\
\text { Facilitar o acesso à } \\
\text { leitura em consideração } \\
\text { a valores culturais que o } \\
\text { livro representa e sua } \\
\text { importância industrial e } \\
\text { econômica. }\end{array}$ & $\begin{array}{l}\text { rias como agentes } \\
\text { „rais; necessidade } \\
\text { arantir a } \\
\text { alidade e } \\
\text { rsidade cultural da } \\
\text { istria e comércio do } \\
\text { rodução } \\
\text { lógica: leitura com } \\
\text { cultural; livro com } \\
\text { ortância industrial e } \\
\text { nômica. }\end{array}$ \\
\hline
\end{tabular}

Observação: A diversidade cultural não é mencionada em outro lugar nas leis avaliadas.

Na lei de Galicia (Ley 5/2012, de 15 de junio, de bibliotecas de Galicia), encontramos o reconhecimento da cultura como necessidade e de que ela não é homogênea, acompanhado das linhas de ação: apoio específico a cultura e língua considerados próprios da região; criação de coleção ao "interesse local"; apoio a "criação cultural"; criação de um espaço público de debate e educação social; e seleção consciente em relação a diversidade cultural.

O reconhecimento e as linhas se complementam, demonstrando apoio às bibliotecas no âmbito estudado. 
$\mathrm{Na}$ lei das Illes Balears (Ley 19/2006, de 23 de noviembre, del Sistema Bibliotecario de las Illes Balears) encontramos o reconhecimento da função da biblioteca em estratégias para a cultura; e de envolvimentos da biblioteca com instituições e órgãos sociais, e também as linhas de ação: biblioteca como centro de ação cultural; promoção e ensino de línguas visando uma "aproximação" entre pessoas que falam diferentes idiomas; adaptação da biblioteca em função da comunidade; extensão de serviços bibliotecários; facilitação de empréstimo e serviços bibliotecários para leitores impossibilitados de aceder a biblioteca e a hospitais, prisões, residência e centros de acolhimento.

O reconhecimento problematiza as questões estratégicas da biblioteca em questões culturais, e estabelece linhas de ações mais específicas, já apresentando um assumir de uma diversidade resultante da diversidade linguística e propondo iniciativas nesse âmbito. A aproximação da biblioteca com instituições de apoio social e a participação da mesma em ambientes de reclusão também demonstra o apoio a linhas de ação voltadas a comunidade em uma postura ativa da biblioteca.

Com relação ao Real Decreto-ley: Ley 10/2007, de 22 de junio, de la lectura, del libro y de las bibliotecas, mesmo tendo os capítulos específicos sobre as bibliotecas e as bibliotecas públicas, a diversidade cultural é mencionada apenas no "Artículo 7. Promoción de la industria editorial y del comercio del libro". Alguns dos reconhecimentos identificados no documento foram das "livrarias como agentes culturais" e da "necessidade de garantir a pluralidade e diversidade cultural da indústria e comércio do livro". Esse aspecto, embora não esteja vinculado diretamente nos aspectos específicos de bibliotecas públicas abordados no Real Decreto, acabam por influenciá-las, ao demonstram a preocupação da indústria em respeito a diversidade, visando assim a garantia de uma oferta mais diversa, que poderá, ao menos parcialmente, incorporada em bibliotecas públicas.

\section{Conclusões}

O paradigma custodial parece permear todo o serviço bibliotecário, que legalmente evolui para financiamentos, políticas e apoios que focam na ampliação de bibliotecas digitais como ferramenta de ampliação do acesso, mas sem discussões especificamente para o apoio do desenvolvimento de serviços voltados a culturas que não se encontram plenamente representadas no panorama atual, muitas vezes pautado em uma instituição inicialmente proposta com o objetivo de controle e/ou naturalização ou unificação de determinada cultura enquanto dominante. 
No caso brasileiro, os documentos assumem uma posição de livro, leitura e escrita que apresenta uma poetização do acesso e acaba por desconsideram as nuances da apropriação.

No caso da Espanha notamos avanços na perspectiva deste estudo, mesmo que de forma isolada (já que os avanços foram identificados principalmente e diretamente no caso das duas leis de comunidades avaliadas), que não só trazem o tema como relevante, mas também apresentam linhas de ação correspondentes.

De maneira geral parece haver uma confusão em relação ao significado do próprio conceito de cultura e diversidade cultural, muitas vezes mencionados de forma superficial e/ou acompanhados de outros termos redundantes ou sem relação ou, nos piores casos, com contextos contrários e/ou de desrespeito a diversidade cultural, e esse foi o principal aspecto encontrado e considerado como significativo para afirmar que a legislação avaliada não poderia ser considerada como fortalecedora da diversidade cultural, mas sim neutra ou até mesmo contrária a ela.

A ineficiência das leis e documentos em reconhecer a diversidade cultural como um fator de impacto em Bibliotecas Públicas se constitui um desafio para que o os bibliotecários atuantes em essas instituições tenham o apoio institucional adequado para a problematização do tema, o que resulta em iniciativas isoladas e pouco visibilizadas de atuação com esse intuito.

Ainda que tenha sido possível identificar essa ineficiência, clarificamos que os resultados dizem respeito apenas a legislação avaliada, selecionada de acordo aos objetivos desse trabalho, deixando então a sugestão de que futuras investigações continuem a análise em outras leis vigentes nos países, o que pode contribuir para a identificação de que esta preocupação possa estar presente em diferentes níveis e/ou em outras esferas legislativas.

\section{Referências}

ALMEIDA JÚNIOR, O. F. Biblioteca pública: avaliação de serviços. Londrina: Eduel, 2013. Disponível em:

http://www.uel.br/editora/portal/pages/arquivos/biblioteca\%20publica digital.pdf/. Acesso em: 23 abr. 2019.

BRASIL. Assessoria de Comunicação, Ministério da Cultura. 2018. MinC anuncia investimentos de quase $R \$ 9$ milhões nas áreas de literatura, bibliotecas e museus. Disponível em: http://www.cultura.gov.br/noticiasdestaques/-/asset publisher/OiKX3xIR9iTn/content/minc-anuncia-investimentos-de- 
quase-r-9-milhoes-nas-areas-de-literatura-bibliotecas-e-museus/10883/. Acesso em: 06 nov. 2018.

BRASIL. Lei no 13.696, de 12 de julho de 2018. Institui a Política Nacional de Leitura e Escrita. Diário Oficial da União: seção 1, Brasília, D.F., p. 1, 13 jul. 2018.

BRASIL. Ministério da Cultura. Caderno do PNLL: Edição atualizada e revisada em 2014. 2014. Disponível em:

http://www.cultura.gov.br/documents/10883/1171222/cadernoPNLL 2014ab.pdf/df8f 8f20-d613-49aa-94f5-edebf1a7a660/. Acesso em: 06 nov. 2018.

BRASIL. Plano Nacional do Livro e Leitura - PNLL. Disponível em: http://www.cultura.gov.br/pnll/. Acesso em: 10 jul. 2018.

CERLALC et al. Reunión Regional sobre el Estado Actual y las Estrategias para el Desarrollo de los Servicios de Bibliotecas Públicas en América Latina y el Caribe: Informe Final. Caracas: UNESCO, 1982. Disponível em: http://unesdoc.unesco.org/images/0005/000525/052531sb.pdf/. Acesso em: 23 abr. 2019.

ESPAÑA. Comunidad Autónoma de Galicia. Ley 5/2012, de 15 de junio, de bibliotecas de Galicia. «DOG», núm. 122, Galicia, 27 jun. 2012.

ESPAÑA. Comunidad Autónoma de las Illes Balears. Ley 19/2006, de 23 de noviembre, del Sistema Bibliotecario de las Illes Balears. «BOIB», núm. 169, Illes Balears, 30 nov. 2006.

ESPAÑA. Ministerio de Cultura. Real Decreto 582/1989, de 19 de mayo. Aprueba el Reglamento de Bibliotecas Públicas del Estado y del Sistema Español de Bibliotecas. Boletín Oficial del Estado, n.129, 31 mayo 1989. ESPAÑA. Real Decreto-ley: Ley 10/2007, de 22 de junio, de la lectura, del libro y de las bibliotecas. Boletín Oficial del Estado, n.150, 23 jun 2007.

FERREIRA, M. M. Políticas públicas de informação e políticas culturais: e as bibliotecas públicas para onde vão? TransInformação, Campinas, 18(2):113-122, maio/ago., 2006.

IFLA; UNESCO. Manifiesto IFLA por la Biblioteca multicultural: la biblioteca multicultural: portal de acceso a una sociedad de culturas diversas en diálogo. 2008. Disponível em:

http://archive.ifla.org/VII/s32/pub/MulticulturalLibraryManifestoes.pdf/. Acesso em: 23 abr. 2019.

MALHEIRO, A. ; RIBEIRO, F. Paradigmas serviços e mediações em Ciência da Informação. Recife: Nectar, 2011.

ORLANDI, Eni Puccinelli. Análise de discurso: princípios e procedimentos. 7. ed. Campinas: Pontes, 2007. 
PAIVA, M. A. M. Bibliotecas públicas: políticas do Estado brasileiro de 1990 a 2006. 2008. Dissertação (Mestrado em Ciência da Informação) Universidade Federal de Minas Gerais, Escola de Ciência da Informação. Disponível em:

http://www.bibliotecadigital.ufmg.br/dspace/bitstream/handle/1843/ECID7HUKTJ/disserta o marilia.pdf?sequence=1/. Acesso em: 23 abr. 2019.

PARREIRA, Z. M. C. A regulamentação legal das bibliotecas públicas em Portugal. Tese apresentada à Universidade de Évora para obtenção do Grau de Doutor em Ciências da Informação e Documentação. Évora, maio de 2018.

RASTELI, A.; CALDAS, R. Mediação cultural na biblioteca pública para a cultura de paz e integração social. REBECIN, v.4, n.2., p.44-57, jul./dez. 2017. Disponível em:

http://abecin.org.br/portalderevistas/index.php/rebecin. Acesso em: 23 abr. 2019.

SILVA, Maria Alice Siqueira Mendes e. Sobre a análise do discurso. Revista de Psicologia da UNESP, Assis, v. 4, n. 1, 2005.

SUAIDEN, E. J. A biblioteca pública no contexo da sociedade da informação. Ciência da Informação, Brasília, v. 29, n. 2, p. 52-60, maio/ago. 2000. 